\title{
Preparation of Ni-Co Alloy Foils by Electrodeposition
}

\author{
Yu-Fang Yang, Bin Deng, Zhao-Hui Wen \\ Department of Chemistry and Life Science, XiangNan University, Chenzhou, China \\ E-mail:zzyufang@163.com \\ Received February 13, 2011; revised February 27, 2011; accepted March 5, 2011
}

\begin{abstract}
Electrodeposition of Ni-Co alloy foils on titanium substrate was performed in an acid chloride-sulphate bath. The influences of electrodeposition parameters such as current density, temperature, $\mathrm{pH}$ value, cobalt sulphate and saccharin concentration on composition and current efficiency were investigated in detail. The morphology and the microstructure of deposits were analyzed by SEM and XRD, respectively. The results indicated that the optimum parameters were current density $3-4 \mathrm{~A} / \mathrm{dm}^{2}, \mathrm{pH} 2-3$, temperature $40-50^{\circ} \mathrm{C}$, cobalt sulphate $20 \mathrm{~g} / \mathrm{l}$ and saccharin $2-3 \mathrm{~g} / \mathrm{l}$. Chemical analysis of the deposits by EDS revealed anomalous $\mathrm{Ni}-\mathrm{Co}$ codeposition occured in this system. The SEM showed that hydroxide particles were not present on the surface and that fine-grain, smooth and compact Ni-Co alloy deposits were obtained. The crystallographic structures of Ni-Co alloy foils were the fcc Ni solid solution. The Ni-Co alloy foils with Co content $17.3-37.2 \mathrm{wt} \%$ and thickness of $20-45 \mu \mathrm{m}$ were bright with low residual stress and super toughness.
\end{abstract}

Keywords: Nickel-Cobalt, Alloy Foil, Electrodeposition

\section{Introduction}

Ni-Co alloy foil exhibits many excellent properties such as corrosion resistance, ductility, brightness, good strength, hardness and stable beneficial magnetic properties. So Ni-Co alloy foils are typical magnetic materials applicable in several fields, such as soft-magnetic and giant-magneto-resistive (GMR) materials [1-3]. Ni-Co alloy foils can be fabricated in several methods such as smelting and electrodeposition. However, the method of electrodeposition is the simplest, most economical, reliable and reproducible technique. Experimental studies on the electrodeposition of Ni-Co alloy by DC current or pulse currents were carried out by a number of researchers [4-15]. The functional properties of electrodeposited $\mathrm{Ni}$-Co alloy foil depend greatly on their composition, which should be strongly affected by deposition parameters. In this paper, no complexing agent was used, Ni-Co alloy foils with a wide range of alloy composition are prepared by changing electrodeposition parameters. The influences of electroplating parameters on the compositions of Ni-Co alloy foils and the current efficiency were discussed.

\section{Experimental}

The Ni-Co alloy foils with thickness up to $45 \mu \mathrm{m}$ were produced from an electrolyte composed of $200 \mathrm{~g} / \mathrm{l}$ $\mathrm{NiSO}_{4} \cdot 6 \mathrm{H}_{2} \mathrm{O}, 45 \mathrm{~g} / \mathrm{l} \mathrm{NiCl} \cdot 6 \mathrm{H}_{2} \mathrm{O}, 20 \mathrm{~g} / \mathrm{l} \mathrm{CoSO}_{4} \cdot 7 \mathrm{H}_{2} \mathrm{O}, 30$ $\mathrm{g} / 1 \mathrm{H}_{3} \mathrm{BO}_{3}, 2 \mathrm{~g} / \mathrm{l}$ saccharin and $0.1 \mathrm{~g} / 1$ wetting agent. $\mathrm{H}_{3} \mathrm{BO}_{3}$ was added as $\mathrm{pH}$ buffer, saccharin was used as brightening agent to reduce the deposit stress. All plating solutions were prepared from deionized water and analytical grade chemical reagent. A PHS- 25 digital $\mathrm{pH}$ meter measured the $\mathrm{pH}$ of the solutions, and the $\mathrm{pH}$ was adjusted to appropriate values with suitable additions of dilute hydrochloric acid or sodium hydroxide. A $250 \mathrm{ml}$ rectangular cell with agitated electrolyte was used as the plating bath. The volume of the solution was approximately $200 \mathrm{ml}$. Electrolytic nickel was used as an anode. The substrate material was high purity titanium sheet with the thickness of $1 \mathrm{~mm}$.

Prior to deposition, the substrate surfaces with dimensions of $2.5 \times 4 \mathrm{~cm}^{2}$ were polished mechanically with silicon carbide emery paper. After polishing, the substrates were rinsed thoroughly in distilled water, and then dipped in the mixed dilute solution of $10 \mathrm{wt} \% \mathrm{HNO}_{3}$ and $10 \mathrm{wt} \% \mathrm{HF}$ for activation for $30 \mathrm{~s}$, and then degreased in acetone and rinsed with deionized water. The distance between the anode and cathode was $5 \mathrm{~cm}$ and the area ratio of anode to cathode was 2 . The depositions were carried out at various solution $\mathrm{pH}$ values from 1 to 5 , and different electrolyte temperature $(20-60)^{\circ} \mathrm{C}$. The constant current deposition was employed at different cur- 
rent densities ranging from $3 \mathrm{~A} / \mathrm{dm}^{2}$ to $7 \mathrm{~A} / \mathrm{dm}^{2}$ from a DC stabilized voltage supply. Electrodeposition was carried out for $15 \mathrm{~min}$.

After electrodeposition, the Ni-Co alloy foil was peeled off from the titanium substrate and rinsed with pure water and then dried. The chemical composition of Ni-Co alloy foils was determined by using an EDXGENESIS 60S energy dispersive spectrum analysis (EDS). According to Faraday's law, the cathodic current efficiency was calculated from the foil weight. The morphology of Ni-Co alloy foils was examined by a JSM6360LV scanning electron microprobe (SEM). The crystallographic structure of the alloy foil was determined by $\mathrm{X}$-ray diffraction (XRD) (Rigaku, D/Max2500) at (40 kv, $450 \mathrm{~mA}$ ) using $\mathrm{Ni}$ filter and $\mathrm{Cu} \alpha$-radiation. The scan

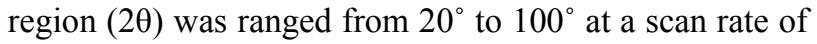
$0.02 \%$ s.

In order that the variation of alloy composition and cathodic efficiency as a function of the parameters might be easily compared, the results obtained were plotted in the same figure. Thus, the curve referring to the scale on the left hand side of the figure illustrated the cobalt content in the deposit, while the curve referring to the right hand side indicated the current efficiency.

\section{Results and Discussion}

\subsection{Influence of Current Density}

The influence of current density at $22^{\circ} \mathrm{C}, \mathrm{pH} 2$ on the cobalt weight percent in the Ni-Co alloy foils and the cathodic current efficiency is shown in Figure 1. It is observed that the Co weight percent in the deposits increases significantly as current density increases and eventually reaches a maximum of $35.7 \mathrm{wt} \%$ at about $4 \mathrm{~A} / \mathrm{dm}^{2}$. With a further increase in the current density, the weight percent of Co decreases gradually. The solution gave smooth and bright deposit with super hardness and ductility over current density range between 3 to $4 \mathrm{~A} / \mathrm{dm}^{2}$, whereas the deposit was undesirable in other current density range. When the current density was lower than $3 \mathrm{~A} / \mathrm{dm}^{2}$, the deposits were brighter, but their toughness decreased. When the current density was higher than $5 \mathrm{~A} / \mathrm{dm}^{2}$, the deposit at the edge was burnt. Especially when the current density increased to $6 \mathrm{~A} / \mathrm{dm}^{2}$, the obtained deposits was dull with green attachments appeared on the surface and it was seriously burnt at high current density region.

It is also noticed that the current efficiency decreases with current density, which indicates an increase in the rate of hydrogen discharge. At $3 \mathrm{~A} / \mathrm{dm}^{2}$, the current efficiency is $57.6 \%$, and it decreases to $31.5 \%$ at $5 \mathrm{~A} / \mathrm{dm}^{2}$. Over the current density range of $5 \mathrm{~A} / \mathrm{dm}^{2}$ to $7 \mathrm{~A} / \mathrm{dm}^{2}$, the current efficiency does not change much. At high current

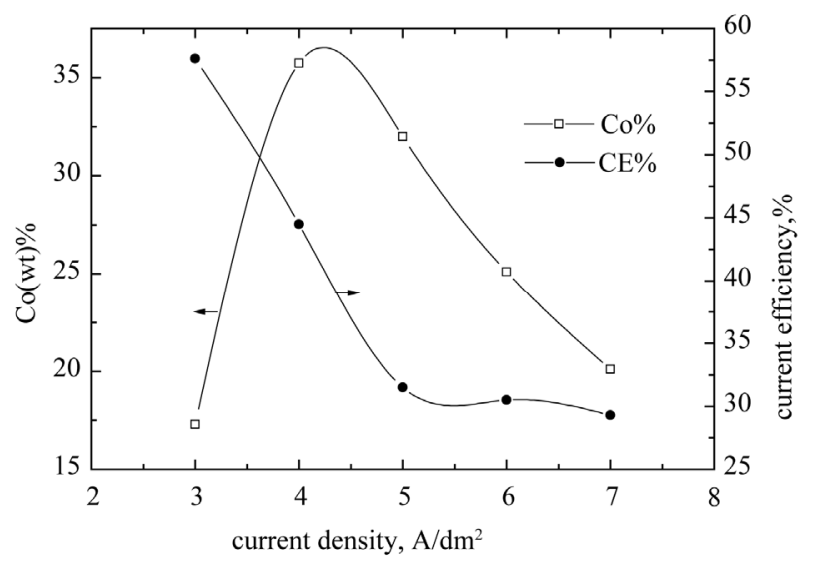

Figure 1. Influence of current density on Ni-Co alloy foil electrodeposition at $\mathrm{pH} 2,22^{\circ} \mathrm{C}$.

density, the low cathodic efficiency could be due to the predominance of the hydrogen reduction reaction. The advantage of using a low current density is that the cathodic current efficiency is high. A further increase in current density leads the deposition rate and the Co weight percent in the deposit decrease. Therefore the current density range between 3 to $4 \mathrm{~A} / \mathrm{dm}^{2}$ is taken as optimum current density and $4 \mathrm{~A} / \mathrm{dm}^{2}$ is used in the remaining experiments.

\subsection{Influence of Temperature}

The influence of bath temperature at $\mathrm{pH} 2$ and current density $4 \mathrm{~A} / \mathrm{dm}^{2}$ on the composition of Ni-Co alloy deposits and the current efficiency is shown in Figure 2. It is found that the Co content in the deposits is lower at the low temperature. And the Co content in the deposit is only $23.3 \mathrm{wt} \%$ at temperature of $20^{\circ} \mathrm{C}$. With increasing temperature, the Co content in the deposit increases rapidly and reaches a maximum value of $34.1 \mathrm{wt} \%$ at temperature of $30^{\circ} \mathrm{C}$. After this, with a further increase of

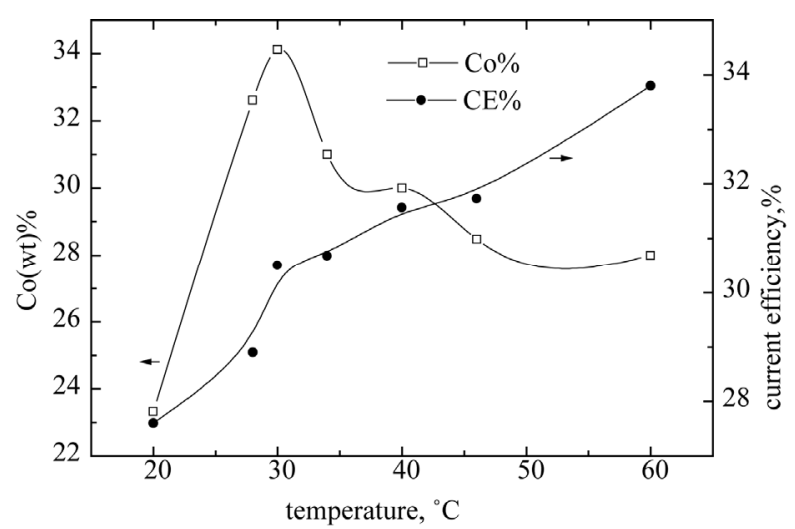

Figure 2. Influence of temperature on Ni-Co alloy foil electrodeposition at $\mathrm{pH} 2,4 \mathrm{~A} / \mathrm{dm}^{2}$. 
temperature, the weight percent of $\mathrm{Co}$ in the deposits decreases gradually, however the decreased amount is smaller.

It is noticed that there is a steady increase in current efficiency with gradual increase in temperature. At $20^{\circ} \mathrm{C}$, the current efficiency is $27.6 \%$, and it increases to $33.8 \%$ at $60^{\circ} \mathrm{C}$. In the mean time, the brightness of the deposits improves, the hydrogen evolution reaction weakens, the quality of the deposits is good and the thickness of the deposits increases. At temperature lower than $40^{\circ} \mathrm{C}$, a violent hydrogen evolution reaction takes place on the cathode, which consumes a considerable fraction of the current available and consequently makes the thickness of the deposits thinner. At temperature higher than $50^{\circ} \mathrm{C}$, the brightness of the deposit decreases and its compactness is worse. At $60^{\circ} \mathrm{C}$, the deposit is dull grey and brittle, accompanied by phenomenon of charred black with a large number of bubbles produced on the surface. So the optimum temperature range is $40-50^{\circ} \mathrm{C}$, at which the obtained deposits are bright and smooth.

\subsection{Influence of pH Value}

The effect of bath $\mathrm{pH}$ value on the weight percent of cobalt in the deposits and the current efficiency is demonstrated in Figure 3. The curve assumes that the percentage of the cobalt in the deposits increases sharply with increasing the $\mathrm{pH}$ value up to 2 . When the $\mathrm{pH}$ value is at 1 , the Co content in the deposit is $27.1 \mathrm{wt} \%$. When the $\mathrm{pH}$ value increases to 2 , the Co content reaches to the maximum of $37.2 \mathrm{wt} \%$. Above $\mathrm{pH}$ of 2 , the decrease in the amount of cobalt is found. Especially when the $\mathrm{pH}$ value is in the range of 2 to 3 , the Co content decreases sharply with increase of $\mathrm{pH}$. Since then, with the $\mathrm{pH}$ value continues to increase, the Co content decreases slowly.

With gradual increasing the $\mathrm{pH}$ values from 1 to 3 , there was a fast increase in current efficiency which increases from $28.5 \%$ to $37.5 \%$. At higher $\mathrm{pH}$ value greater than 3 , the increase in current efficiency is slow. The hydrogen evolution reaction is found to decrease with increasing the $\mathrm{pH}$ value. Experiments show that when the $\mathrm{pH} \leqslant 1$, intense hydrogen evolution reaction occurred on the cathode, producing a large number of bubbles, the surface of the deposit is neither bright nor smooth with pinholes and pitting on it. At $\mathrm{pH}$ value of 2 - 3, the hydrogen evolution is less, the quality of the deposit is good. The deposit is thick, smooth and bright with good hardness and toughness. When the $\mathrm{pH}$ value increases to 4 or 5 , the deposit is thin, gloomy, not bright, brittleness and burnt edge. Further increase the $\mathrm{pH}$ value, this phenomenon becomes increasing serious. This is because when the $\mathrm{pH}$ value is higher, the $\mathrm{Ni}(\mathrm{OH})_{2}$ and $\mathrm{Co}(\mathrm{OH})_{2}$ are very easily to form in the solution. These insoluble

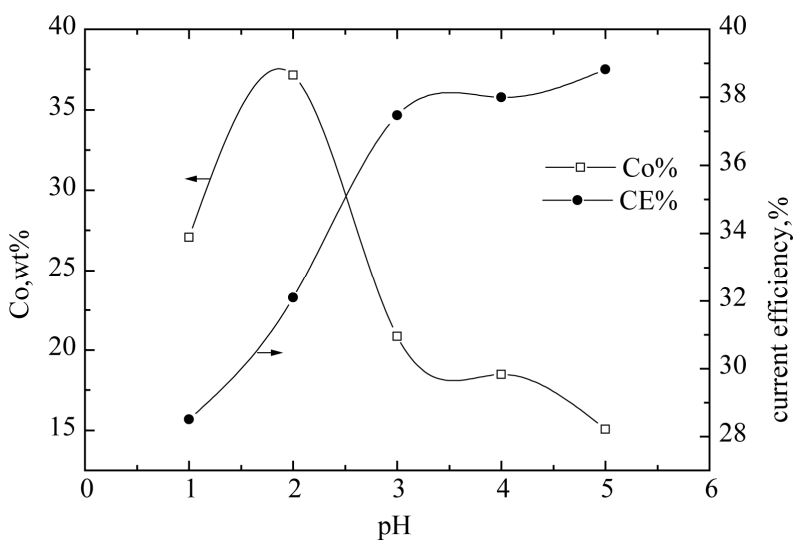

Figure 3. Influence of pH value on Ni-Co alloy foil electrodeposition at $22^{\circ} \mathrm{C}, 4 \mathrm{~A} / \mathrm{dm}^{2}$.

hydroxide adsorbed on the surface of the deposits, prevented the Ni-Co alloy codeposition and their electrocrystallization. At $\mathrm{pH} 2$ to 3, a satisfactory deposit is noticed. In this optimum $\mathrm{pH}$ value range, the cathode current efficiencies are high and the deposit is smooth and bright with fine grain size.

\subsection{Influence of $\mathrm{CoSO}_{4} \cdot 7 \mathrm{H}_{2} \mathrm{O}$ Concentration}

Cobalt sulphate is a main salt in the bath solution. In order to see its effect on the deposit nature, its concentration is varied from 20 to $60 \mathrm{~g} / \mathrm{l}$. Its influence on the compositions of Ni-Co alloy foils and the current efficiency is shown in Figure 4. The content of cobalt increases gradually from $35.7 \mathrm{wt} \%$ to $42.8 \mathrm{wt} \%$ at cobalt sulphate concentration from 20 to $50 \mathrm{~g} / \mathrm{l}$. With a further increase in the $\mathrm{CoSO}_{4}$ concentration, the weight percent of cobalt increases sharply. It can be suggested that increasing concentration of $\mathrm{CoSO}_{4}$ is the reason for an increase in the activity of cobalt ion. The concentration of cobalt sulphate at 20-50 g/l generated bright and smooth deposit

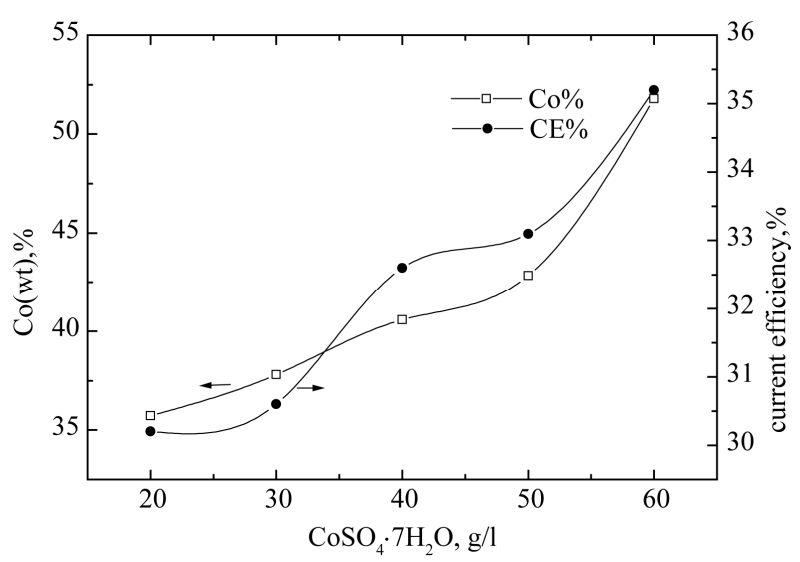

Figure 4. Influence of $\mathrm{CoSO}_{4}$ on Ni-Co alloy foil electrodeposition at $22^{\circ} \mathrm{C}, 4 \mathrm{~A} / \mathrm{dm}^{2}$, $\mathrm{pH} 2$. 
with good toughness and super quality. Further increase in concentration to $60 \mathrm{~g} / 1$ does not introduce any improvement in the nature of deposit. When the cobalt sulphate concentration is more than $60 \mathrm{~g} / \mathrm{l}$, the deposit is thin and dull with bad toughness. The edge of the deposit is black, burnt and coarse, the bright range of the deposit is extended to the lower current density region, whereas the higher current density region is covered with undesirable deposit. As the electrodeposition of Ni-Co alloy in this system is amorphous codeposition, the content of $\mathrm{Co}$ can reach a higher value even if at a low $\mathrm{CoSO}_{4} \cdot 7 \mathrm{H}_{2} \mathrm{O}$ concentration. Hence the concentration of cobalt sulphate is fixed at $20 \mathrm{~g} / \mathrm{l}$ in bath solution and is taken as optimum concentration and is used in the experiments. It is notable that the highest Co deposits with Co content of $37.2 \mathrm{wt} \%$ can be produced in this solution.

It is observed that at lower $\mathrm{CoSO}_{4}$ concentration in the range $20-30 \mathrm{~g} / 1$, the current efficiency does not increase significantly. However, increase in the current efficiency of about $2 \%-5 \%$ is observed at $\mathrm{CoSO}_{4}$ concentration of $40-60 \mathrm{~g} / 1$ in the electrolyte. The increase in current efficiency may be attributed to the anomalous codeposition of cobalt with nickel.

\subsection{Influence of Saccharin Concentration}

In this system the saccharin is used as brightener. The addition of saccharin increases the formation of fresh nucleation sites during deposition resulting in the formation of fine grained deposit. Saccharin concentration is varied from 1 to $5 \mathrm{~g} / \mathrm{l}$. Its effect on the weight percent of cobalt in the deposits and the current efficiency is shown in Figure 5. At lower concentration, the deposit is not bright and shows bad ductility. With increase in the concentration of saccharin, the brightness of the deposit improves. The bath solution without saccharin gives dull or semi bright deposit in the current density range of 3 to $7 \mathrm{~A} / \mathrm{dm}^{2}$. The saccharin at lower than $1 \mathrm{~g} / \mathrm{l}$ gives semi bright deposit at $4 \mathrm{~A} / \mathrm{dm}^{2}$. At a concentration of 2 to $3 \mathrm{~g} / \mathrm{l}$, satisfactory bright deposit is obtained. Further increase in the concentration of saccharin does not introduce any improvement in the nature of deposit. The content of cobalt increases from $23.3 \mathrm{wt} \%$ to $36.6 \mathrm{wt} \%$ with increasing the saccharin concentration from 1 to $4 \mathrm{~g} / \mathrm{l}$. It is also noticed the current efficiency increases with saccharin up to $4 \mathrm{~g} / \mathrm{l}$, but the current efficiency increases slowly at saccharin concentration from 2 to $4 \mathrm{~g} / \mathrm{l}$. With a further increase of saccharin concentration, both the Co content in the deposits and the current efficiency decreases sharply. This may be attributed to the higher concentration of saccharin tends to raise the adsorption and the cathodic polarization, and then impedes the $\mathrm{Ni}-\mathrm{Co}$ alloy foil electrodeposition. So the optimum concentration of saccharin should be 2 to $3 \mathrm{~g} / \mathrm{l}$.

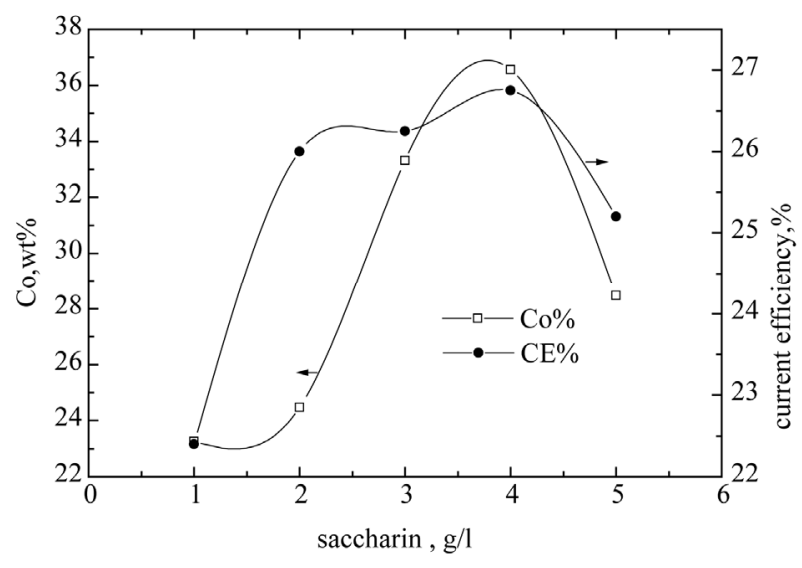

Figure 5. Influence of saccharin on Ni-Co alloy foil electrodeposition at $22^{\circ} \mathrm{C}, 4 \mathrm{~A} / \mathrm{dm}^{2}, \mathrm{pH} 2$.

\subsection{Characteristic, Morphology and Microstructure of Ni-Co Alloy Foils}

Based on the above experiments, a characteristic feature can be found is that in the chloride-sulphate medium system, the $\mathrm{Co} / \mathrm{Ni}$ ratio in the alloy foils is considerably higher than that of in the electrolyte. If cobalt were to deposit on the cathode at a rate corresponding to its concentration in solution, it would yield a cobalt content of $7.1 \mathrm{wt} \%$. The electrodeposited alloy foils, however, shows cobalt content of between $15.1 \mathrm{wt} \%$ and $37.2 \mathrm{wt} \%$. It indicates that the deposition of the less noble metal cobalt is enhanced while the reduction of nickel is inhibited. So the electrodeposition of binary Ni-Co alloy foils exhibits the phenomenon termed anomalous codeposition.

The Ni-Co alloy foils obtained at the optimum conditions with cobalt content of $17.3-37.2 \mathrm{wt} \%$ and thickness of $20-45 \mu \mathrm{m}$. The samples of Ni-Co alloy foils were subjected to bending test. No crack the deposit was noticed even if it was bended by $180^{\circ}$. This indicates the $\mathrm{Ni}-\mathrm{Co}$ alloy foils are of good toughness with low residual stress.

Figure 6 shows the SEM micrographs of the Ni-Co alloy foils with different cobalt contents. The morphology shows uniform spherical fine-grain nodules which are characteristic of cobalt alloy deposits. Hydroxide particles are not observed and all the deposits are bright, metallic and smooth. Obvious grain boundary can be found on the deposit. Compared (a) and (b), it can be seen that the crystal size of the deposit with higher Co content is much smaller.

Figure 7 shows the XRD patterns of the electrodeposited Ni-Co alloy foils with $37 \mathrm{wt} \%$ Co and $35.6 \mathrm{wt} \%$ Co content, respectively. Two sharp peaks in each XRD pattern at the $2 \theta$ of around $44.46^{\circ}$ and $51.8^{\circ}$ are observed clearly. Their main textures are (111) and (200). These high peaks suggest that the Ni-Co alloy deposits may be considered as crystalline in structure. With increase of 


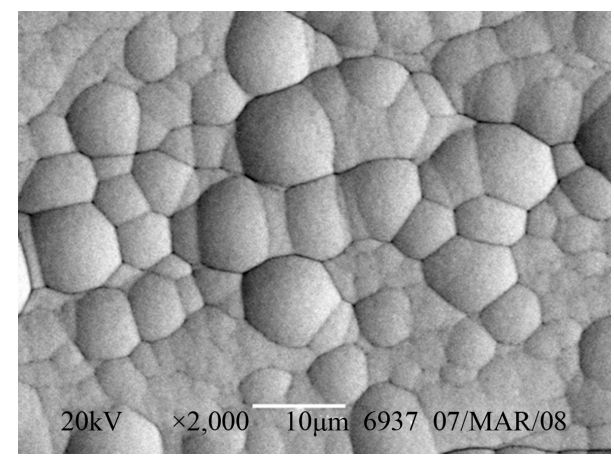

(a)

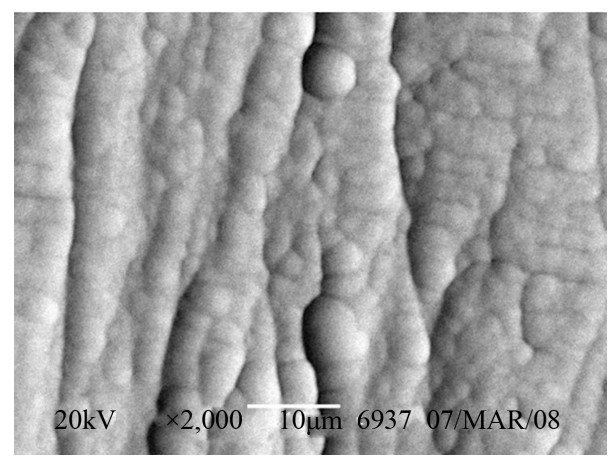

(b)

Figure 6. SEM micrographs of Ni-Co alloy foils (a) 35.6 wt \% Co, (b) 41.5 wt \% Co.

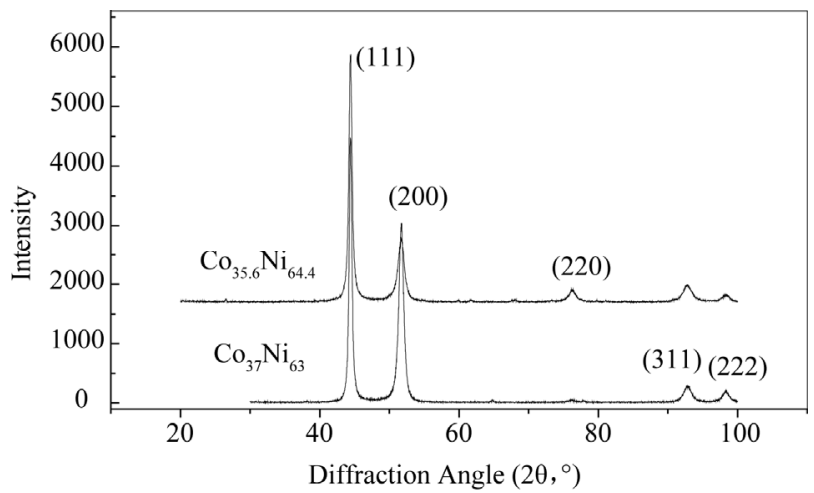

Figure 7. XRD patterns of Ni-Co alloy deposits.

Co content, the intensity of the main peaks increase, and the peak width is broader for deposit with higher Co content indicates decrease in grain size of the deposit. The deposit can be identified as Ni solid solution with a face centred cubic (fcc) structure.

\section{Conclusions}

Bright Ni-Co alloy foils could be electrodeposited from acid chloride-sulphate bath by optimization of the electrodeposition parameters. The bright deposit current density, temperature and $\mathrm{pH}$ value range is $3-4 \mathrm{~A} / \mathrm{dm}^{2}, 40$ - $50^{\circ} \mathrm{C}$ and $2-3$, respectively. The optimized concentration of cobalt suphate is $20 \mathrm{~g} / \mathrm{l}$ and that of saccharin is 2 $3 \mathrm{~g} / \mathrm{l}$. The crystallographic structure of Ni-Co deposited foil is the fcc Ni solid solution. The deposit is uniform fine grained. The deposit shows good toughness and low residual stress.

\section{Acknowledgements}

The authors are grateful to Science and Technology Agency of Hunan Province, China, for providing financial assistance; Grant No. 2007FJ3028.

\section{References}

[1] C. A. Moina and M. Vazdar, "Electrodeposition of NanoSized Nuclei of Magnetic Co-Ni Alloys onto n-Si (100)," Electrochemistry Communications, Vol. 3, 2001, pp. 159163. doi:10.1016/S1388-2481(01)00114-X

[2] M. Srivastava, V. E. Selvi, V. K. W. Grips and K. S. Rajam, "Corrosion Resistance and Microstructure of Electrodeposited Nickel-Cobalt Alloy Coatings," Surface \& Coatings Technology, Vol. 201, 2006, pp. 3051-3060. doi:10.1016/j.surfcoat.2006.06.017

[3] L. Peter, J. Padar, E. Toth-Kadar, A. Cziraki, P. Soki, L. Pogany and I. Bakonyi, "Electrodeposition of $\mathrm{Co}-\mathrm{Ni}-\mathrm{Cu} /$ $\mathrm{Cu}$ Multilayers 1. Composition, Structure and Magnetotransport Properties," Electrochimica Acta, Vol. 52, 2007, pp. 3813-3821. doi:10.1016/j.electacta.2006.10.058

[4] A. N. Correia and S. A. S. Machado, "Electrodeposition and Characterisation of Thin Layers of Ni-Co Alloys Obtained from Dilute Chloride Baths," Electrochimica Acta, Vol. 45, 2000, pp. 1733-1740. doi:10.1016/S0013-4686(99)00405-3

[5] D. Golodnitsky, Y. Rosenberg and A. Ulus, "The Role of Anion Additives in the Electrodeposition of Nickel/Cobalt Alloys from Sulfamate Electrolyte," Electrochimica Acta, Vol. 47, 2002, pp. 2707-2714. doi:10.1016/S0013-4686(02)00135-4

[6] A. Bai and C.-C. Hu, "Iron-Cobalt and Iron-CobaltNickel Nanowires Deposited by Means of Cyclic Voltammetry and Pulse-Reverse Electroplating," Electrochemistry Communications, Vol. 5, 2003, pp. 78-82. doi:10.1016/S1388-2481(02)00540-4

[7] A. Bai and C.-C. Hu, "Composition Controlling of $\mathrm{Co}-\mathrm{Ni}$ and $\mathrm{Fe}-\mathrm{Co}$ Alloys Using Pulse-Reverse Electroplating through Means of Experimental Strategies," Electrochimica Acta, Vol. 50, 2005, pp. 1335-1345. doi:10.1016/j.electacta.2004.07.055

[8] E. Gomez, S. Pane and E. Valles, "Electrodeposition of $\mathrm{Co}-\mathrm{Ni}$ and $\mathrm{Co}-\mathrm{Ni}-\mathrm{Cu}$ Systems in Sulphate-Citrate Medium," Electrochimica Acta, Vol. 51, 2005, pp. 146-153. doi:10.1016/j.electacta.2005.04.010

[9] B. Chi, J. Li, X. Yang, Y. Gong and N. Wang, "Deposition of Ni-Co by Cyclic Voltammetry Method and Its Electrocatalytic Properties for Oxygen Evolution Reaction," International Journal of Hydrogen Energy, Vol. 30, 
2005, pp. 29-34. doi:10.1016/j.ijhydene.2004.03.032

[10] B. Tury, M. Lakatos-Varsanyi and S. Roya, "Ni-Co Alloys Plated by Pulse Currents," Surface \& Coatings Technology, Vol. 200, 2006, pp. 6713-6717. doi:10.1016/j.surfcoat.2005.10.008

[11] W. E. G. Hansal, B. Tury, M. Halmdienst, M. L. Varsanyi and W. Kautek, "Pulse Reverse Plating of Ni-Co Alloys: Deposition Kinetics of Watts, Sulfamate and Chloride Electrolytes," Electrochimica Acta, Vol. 52, 2006, pp. 1145-1151. doi:10.1016/j.electacta.2006.07.012

[12] V. D. Jovic, B. M. Jovic and M. G. Pavlovic, "Electrodeposition of Ni, Co and Ni-Co Alloy Powders," Electrochimica Acta, Vol. 51, 2006, pp. 5468-5477. doi:10.1016/j.electacta.2006.02.022

[13] V. D. Jovic, B. M. Jovic, V. Maksimovic and M. G. Pav- lovic, "Electrodeposition and Morphology of Ni, Co and Ni-Co Alloy Powders Part II. Ammonium Chloride Supporting Electrolyte," Electrochimica Acta, Vol. 52, 2007, pp. 4254-4263. doi:10.1016/j.electacta.2006.12.003

[14] A. Dolati, M. Sababi, E. Nouri and M. Ghorbani, "A Study on the Kinetic of the Electrodeposited Co-Ni Alloy Thin Films in Sulfate Solution," Materials Chemistry and Physics, Vol. 102, 2007, pp. 118-124. doi:10.1016/j.matchemphys.2006.07.009

[15] R. Orinakova, A. Oriňák, G. Vering, I. Talian, R. M. Smith and H. F. Arlinghaus, "Influence of $\mathrm{pH}$ on the Electrolytic Deposition of Ni-Co Films," Thin Solid Films, Vol. 516, 2008, pp. 3045-3050. doi:10.1016/j.tsf.2007.12.081 